\title{
OBRAZY W DZIAEANIU. STRATEGIE INTERWENCYJNE WSPÓŁCZESNYCH BADAŃ WIZUALNYCH
}

Sięgamy po nie, żeby zapamiętać, sprawić, by ktoś pamiętał, albo podzielić się z kimś czymś, co się zauważyło i uznało za istotne. Mieć pretekst do rozmów lub zabić nudę. Udekorować biurko, zareklamować produkt, upublicznić twarz poszukiwanego przestępcy bądź skłonić go do przyznania się do winy. Niezależnie od tego, jak zwykliśmy o nich myśleć, w fotografii czy wideo nigdy nie chodziło o zatrzymywanie świata, ale o puszczanie go w ruch określonym torem. Technologie wizualne popularyzywały się i popadały w zapomnienie wcale nie ze względu na dostarczany przez nie zapis obrazu, ale dlatego że wytwarzały go jako materialny obiekt, którym można było albo nie można było posłużyć się do uzyskania określonego efektu (por. Wright 2008, s. 3). Codziennym doświadczeniom obcowania z obrazami fotograficznymi w mniejszym czy większym stopniu od zawsze towarzyszyła refleksja nad możliwym wykorzystaniem potencjału technicznej reprezentacji do celów społecznych, snuta przez uczonych, społeczników, decydentów politycznych lub hobbystów.

Podstawowy kierunek takiego myślenia był zbieżny z czynnikami, które powołały do życia akademickie nauki społeczne. Rozwój socjologii miał ścisłe odniesienia do ruchów postępowych, reformatorskich i filantropijnych (Burawoy 2010, s. 548); teoria społecznej organizacji miała ocalić ideę modernistycznego postępu, dostarczając wniosków pozwalających rozwiązać problemy, z którymi mierzyły się europejskie metropolie w konsekwencji procesów uprzemysłowienia. Antropologia, pełniąca funkcję zamorskiej delegacji tej samej utopii, pomagała doprecyzować rozważania przez skonfrontowanie organizacji społeczeństw państw zachodnich z - jak wówczas utrzymywała - jej prostszymi

Adres do korespondencji: maciejf@amu.edu.pl 
formami, występującymi we wspólnotach „pierwotnych”; nierzadko kolonizując przy tym przedmiot swoich badań na zachodnioeuropejską modłę, umożliwiając i legitymizując ekonomiczny oraz kulturowy kierunek rozwoju państw centrum.

Fotografia służyła tym samym ideom planowania i postępu, czyniąc zadość ewidencyjnym potrzebom krajów zachodnich, które modernizowały swoje służby porządkowe (Rouillé 2007), albo dokumentując sprawność rodzącego się systemu opieki społecznej. Zadaniom tym były poświęcone między innymi fotografie Radży Lali Deen Dayala, który portretował życie ubogich "przed” i „po” państwowej interwencji (Rosenblum 2005, s. 352), lub zdjęcia Francis Benjamin Johnston, która w roku 1899 zaangażowała się w dokumentowanie wyników Hampton Institute - szkoły, której celem była walka z ubóstwem Murzynów i Indian metodą ich odpowiedniej edukacji (Rosenblum 2005 , s. 361). Stylizowane fotografie pensjonariuszy sprzątających kurze lub polerujących szkła miały tu dowodzić zasadności angażowania publicznych pieniędzy w walkę z biedą oraz mobilizować środki na dalsze państwowe działania w tym zakresie ${ }^{1}$.

Nie tylko państwom, ale i umacniającym się naukom społecznym odpowiadała urzeczywistniana przez fotografię idea światoobrazu (Heidegger 1977). Nowe wynalazki wizualne zwieńczyły ideały nowoczesnego poznania — standardyzowały postrzeganie „zabezpieczając [ów] projekt rygorem w postępowaniu" (Heidegger 1977, s. 133). Wydawało się, że techniczne obrazy umożliwiają utrwalenie, uzasadnienie (dowód: świat istotnie przedstawiania się tak, jak go widzimy), a następnie archiwizację i analizę rzeczywistości na niespotykaną wcześniej skalę. Gwarantowane reżimem optycznej i chemicznej technologii, kusiły obietnicą pomocy w dzieleniu, zestawianiu, a także koniec końców - zarządzaniu światem i planowaniu go. Spotkanie się tych dwóch sposobów relacjonowania rzeczywistości społecznej - obrazów fotograficznych i nauk społecznych - w kontekście realizowanych przez nie celów pozaakademickich, było jedynie kwestią czasu.

Jednym z pierwszych projektów przypominających dzisiejsze studia stosowane nad wizualnością były badania Margaret Mead, która w okresie drugiej wojny światowej oraz na początku zimnej wojny doradzała rządowi Stanów Zjednoczonych ${ }^{2}$. W pracach Centrum Badań nad Współczesnymi Kulturami, założonego przez nią wspólnie z Ruth Benedict, Mead wykorzystywała

\footnotetext{
${ }^{1}$ Pomoc biednym nie była wówczas wcale tak oczywista - jak słusznie zauważa Noami Rosenblum (2005) - przez długi czas bowiem przyjmowano, że bieda albo le ży w naturze tych, których dotknęła, albo pozostaje i ch w in ą. Nowoczesne państwo dopiero starało się uzasadnić swoją perspektywę welfare state, według której problemy społeczne są raczej wynikiem warunków społecznych, w których bezdomni czy bezrobotni żyją i które instytucje publiczne powinny polepszyć w interesie ogółu.
}

2 Opis projektów Mead, Batesona oraz Colliera za: Pink 2006, s. 82-86. 
przedstawienia wizualne $\mathrm{w}$ dociekaniach nad charakterem narodowym krajów, z którymi Stany Zjednoczone były sprzymieżone, bądź z którymi walczyły ${ }^{3}$. Projekt wspierał również Gregory Bateson (1980), próbując odpowiedzieć na pytanie: „jakiego rodzaju ludźmi są naziści” (kwestia istotna wówczas dla amerykańskiego wywiadu - zainteresowanego możliwościami pozyskania szpiegów) i analizując w tym celu niemiecki film z roku 1933 Hitlerjunge Quex.

Problemy pozaakademickie legły u podstaw również innej fundamentalnej dla rozwoju badań wizualnych pracy - Visual Anthropology: Photography as a Research Method Johna Colliera (1986[1967]). Wśród badań, na podstawie których Collier opisywał możliwości wykorzystania fotografii w naukach społecznych, Sarah Pink (2006, s. 83-84) wymienia między innymi „Vicos”, przedsięwzięcie obliczone na przygotowanie peruwiańskich robotników do obywatelskich obowiązków w realiach życia pozbawionego kolonialnej kontroli. Wizualną dokumentację efektów projektu (dopatrywano się ich w symbolicznych i materialnych przemianach miasteczka Vicos) poddano analizie jakościowej i statystycznej. Kolejny projekt to „Alaskan Eskimo Education” (1973), w którym Collier sprawdzał, jaki wpływ na rdzenne wspólnoty Eskimosów wywiera północnoamerykański system edukacji, oddziałujący za pośrednictwem szkół. Badania te stanowiły część większego, interdyscyplinarnego przedsięwzięcia, którego celem było uzyskanie odpowiedzi na pytanie, w jaki sposób białe społeczeństwo powinno edukować rdzennych mieszkańców Ameryki Północnej. Wkład Colliera stanowił raport, złożony w Ministerstwie Edukacji Stanów Zjednoczonych, oparty na analizie $z$ wykorzystaniem koncepcji wzorów kultury (Benedict 1999), ponaddwudziestogodzinnego materiału filmowego, dokumentującego eskimoskie dzieci w klasach rozmaitych środowisk szkolnych: od szkół misyjnych przez stanowe aż do państwowych.

Badania Mead, Batesona i Colliera wzięte razem składają się na obraz badań wizualnych, który - mimo ogromnego przyrostu prac — nie uległ do dziś zasadniczej zmianie. W dalszym ciągu ich zakres wyznacza - z jednej strony namysł nad rolą obrazu w reprodukowaniu relacji w obrębie zbiorowości ludzkich, $z$ drugiej — refleksja nad jego wykorzystaniem w charakterze narzędzia do zbierania danych o tych zbiorowościach i komunikowania im o wynikach (Frąckowiak, Rogowski 2009). Wiele zmieniło się natomiast jeżeli chodzi o uwagę poświęcaną $\mathrm{w}$ obrębie badań wizualnych refleksji nad ich wykorzystaniem do celów pozaakademickich - o ile kiedyś badania te przyczyniły się do ugruntowania społecznych studiów wizualnych jako obszaru rozważań naukowych, o tyle dzisiaj pozostają zdecydowanie $\mathrm{w}$ cieniu tych drugich ${ }^{4}$. Przeszkadza to

\footnotetext{
3 Fragmenty tych badań Mead opublikowała wraz z Métraux w książce The Study of Culture at a Distance (2000).

4 Poza Sarah Pink (zob. np. 2004, 2006, 2007), Richardem Chalfenem (zob. np. 1971, 1999, 2004) czy Claudią Mitchell (zob. np. 2007, 2008, 2011) trudno znaleźć innych badaczy, którzy od
} 
nie tylko $\mathrm{w}$ popularyzacji, ale również $\mathrm{w}$ refleksji nad ich współczesnym statusem, celami i sposobami wykorzystania. Tym bardziej że od czasów Mead i Colliera wiele się $\mathrm{w}$ tych kwestiach zmieniło. W efekcie - wzrósł również interwencyjny potencjał badań wizualnych, daleko wykraczający dziś poza najbardziej popularny obraz - ograniczający wizualne studia stosowane do badań rynku i ewaluacji kampanii reklamowych.

\section{KONTEKSTY WSPÓŁCZESNYCH WIZUALNYCH BADAŃ STOSOWANYCH}

Pojęcia struktury i funkcji stopniowo ustępują w naukach społecznych pojęciom relacji czy praktyki. Zmianom językowym towarzyszy zmiana w sposobie konceptualizacji organizacji społecznej. Teorie strukturalno-funkcjonalne, wypracowane przede wszystkim na użytek analizy państw narodowych o silnie rozwiniętej sieci instytucji rządowych, okazały się nieefektywne podczas wyjaśniania coraz bardziej złożonych i samoorganizujących się społeczeństw o niejasnych granicach. Globalne migracje sprawiły, że niewielkie przestrzenie zamieszkują dziś osoby o zupełnie różnych przekonaniach politycznych, wartościach, wyznaniach i zwyczajach kulturowych. Nowe ruchy społeczne i rosnący sektor organizacji pozarządowych wyartykułował ich potencjał przekształcania rzeczywistości społecznej. Postępującemu urefleksyjnieniu aktorów społecznych towarzyszy ich rosnące uzależnienie od techniki, której zasad coraz częściej nie są w stanie pojąć, a konsekwencji uwzględnić w swoim działaniu.

Obserwowane przemiany nie tylko zwróciły uwagę teoretyków na konieczność uwzględnienia w koncepcjach organizacji społecznej racjonalności potocznej, refleksyjności i doświadczeń jednostki jako istotnej sprawczości strukturotwórczej (por. np. Schütz 2008; Garfinkel 1984; Berger, Luckmann 2010; Giddens 2003), ale także wymusiły wzięcie pod uwagę pozarefleksyjnych rodzajów wiedzy, jak choćby wiedza wcielona (zob. Kaufmann 2004) czy wiedza delegowana w przedmioty (Latour 2010; Abriszewski 2008; Krajewski 2007, 2008). W rezultacie coraz trudniej wyobrazić dziś sobie socjologiczną czy antropologiczną analizę działania, która redukowałaby je do echa kontekstu instytucjonalnego, stosunków własności, pozycji w strukturze, dyskursu czy innych determinant systemowych z jednej strony, a z drugiej — do świadomości działającego; bez uwzględniania cielesnego, rutynowego i materialnego wymiaru życia aktorów społecznych.

Stopniowe odejście od „wielkich” systemów teoretycznych niesie ze sobą określone konsekwencje dla sposobu planowania jakiejkolwiek interwencji. Pozbywamy się bowiem najoczywistszego, przynajmniej dla socjologii, uzasadnienia tego rodzaju działania: oto naukowiec - dysponujący w punkcie wyjścia

dłuższego czasu systematycznie zajmowaliby się prowadzeniem wizualnych badań stosowanych i teoretyzowaniem na ich temat. 
ustalonym modelem organizacji zbiorowej tłumaczącym, która część systemu odpowiedzialna jest za jakie jego funkcje i w jakich relacjach względem siebie owe części pozostają - widząc patologię $\mathrm{w}$ określonym sektorze, $\mathrm{z}$ dużą dozą pewności proponuje zmianę $\mathrm{W}$ dysfunkcjonalnym elemencie instytucji i oczekuje powrotu do pożądanego stanu. Jeśli jednak przyjmie się, że teorie systemowo-strukturalne w coraz mniejszym stopniu tłumaczą zasady organizacji zbiorowej, to trzeba przystać na przynajmniej częściowe przeformułowanie roli wiedzy eksperckiej w jej społecznych zastosowaniach.

Po pierwsze, podobnie jak w przypadku jednej z ról socjologii krytycznej, $\mathrm{w}$ ramach analizy nauk społecznych, zadaniem wiedzy eksperckiej jest krytyka naturalistycznego modelu wyjaśniania rzeczywistości społecznej — odrzucenie założeń, wedle których życie społeczne cechuje się zasadniczo podobnymi zasadami organizacji jak świat przyrody, oraz przekonania, że należy je konceptualizować i badać przy użyciu teorii i metod wzorowanych na naukach przyrodniczych (Mucha 1986, s. 7). Po drugie, w ramach analizy społeczeństwa ${ }^{5}$, wiedza ekspercka przestaje służyć obmyślaniu proponowanej zmiany tylko $z$ wykorzystaniem własnych teorii. Odpowiada raczej za formułowanie metod współpracy między planującymi zmianę a tymi, którzy mają na niej skorzystać (por. Gliński 1980). Stosowane nauki społeczne, przechodząc na pozycje bardziej organiczne, zyskują jednocześnie wgląd w subiektywne światy aktorów, ich doświadczenia, pozarefleksyjne rutyny oraz materialny kontekst życia, jednym słowem - w to wszystko, co (poza kontekstem instytucjonalnym) uwzględniać dziś musi skuteczna interwencja ${ }^{6}$. Wagę uzyskanej w ten sposób wiedzy w coraz większym stopniu doceniają dziś instytucje publiczne, organizacje pozarządowe oraz przemysł — zdecydowanie bardziej niż kiedyś zainteresowane jakościowymi analizami problemów, z którymi się mierzą (Pink 2006, s. 82).

Rezultatem wskazanych przemian teoretycznych jest także widoczna zmiana tego, w jaki sposób nauki społeczne definiują obraz i jego społeczną

${ }^{5}$ Korzystam tu z rozróżnienia dwóch aspektów socjologii krytycznej dokonanego przez Janusza Muchę (1986, s. 15).

6 Proponowane tu rozumienie interwencji społecznej w dużej mierze jest konsekwencją przyjęcia perspektywy konstruktywistycznej, która ma swoje zalety, ale i wady. Dalej wskazuję na zalety, z wadami próbując sobie częściowo radzić przez wskazanie na sprawczość cielesnego i materialnego wymiaru działania ludzkiego (do których dotarcie uławiają narzędzia wizualne); nie podejmuję jednak szerzej wątku istotnego wpływu, jaki na powstanie i rozwiązywanie problemów społecznych ma ich kontekst instytucjonalny, a także potencjalnych możliwości urefleksyjnienia tego wpływu dzięki wykorzystaniu obrazów. Świadomy zagrożeń, które się z tym pominięciem wiążą, nie rozważam ich jednak tutaj, gdyż celem moim pozostaje nie tyle konfrontowanie rezultatów opisywanej perspektywy z innymi orientacjami w naukach stosowanych, ile prezentacja kierunków rozwoju współczesnych wizualnych badań stosowanych oraz przemian, które te kierunki wytyczyły i określają. Czytelnika zainteresowanego porównaniem mocnych i słabych stron różnych perspektyw teoretycznych wykorzystywanych podczas rozwiązywania problemów społecznych, w tym mocnymi i słabymi stronami perspektywy konstruktywistycznej, odsyłam do pracy Krzysztofa Frysztackiego (2009). 
sprawczość. Również na tym polu stopniowo odchodzimy od charakterystycznego dla strukturalizmu myślenia istotowego, polegającego na uznaniu mediów wizualnych za zdeterminowane właściwościami technologicznymi bądź ideologicznymi, co zawęża rozważania do problemu, czy obrazy przedstawiają wiarygodnie, czy też nie, a koniec końców - do pytania o to, czego w istocie są odbiciem (por. Pinney 2004, s. 8). Zmiana użytków czynionych z medium $\mathrm{i}$ jego statusu oraz jego popularyzacja w codziennym, prywatnym kontekście życia aktorów społecznych przekonują badaczy, że reprezentacja techniczna sama $z$ siebie nie ma żadnych właściwości, zyskuje je za każdym razem dopiero w kontekście użycia (por. Rouillé 2007). Fotografię czy wideo należy zatem rozpatrywać, bardziej niż na planie ontologii zapisu, w odniesieniu do „lokalnych kultur wizualnych" (Pink 2008). Przyjęcie założenia, że obrazy zyskują swoje znaczenie dopiero w ramach konkretnych praktyk, prowadzi do zerwania $z$ pojmowaniem ich $w$ kategoriach ograniczonej kadrem reprezentacji - akcent zostaje przesunięty na sposób, $\mathrm{w}$ jaki owa reprezentacja staje się przedmiotem działania jednostki, a także sposób, w jaki to działanie modyfikuje (zob. np. Latour 1990; Gell 1998; Edwards, Hart 2004; Krajewski 2008a). Owe modyfikacje, równie dobrze jak rezultatem zarejestrowanego obrazu, mogą być wtedy wynikiem czynności wykonywania zdjęć, technologii ich przechowywania oraz upowszechniania, a także budowanych wokół obrazów interakcji (Drozdowski, Krajewski 2010).

\section{MAPA STRATEGII}

Mnożenie przykładów przedsięwzięć będących rezultatem zachodzących przemian i podejmowanych $z$ wykorzystaniem mediów wizualnych miałoby ograniczony sens, jeżeli nie towarzyszyłaby temu próba wyodrębnienia określonych form czy logik, które zarządzają dziś interwencjami w ramach wizualnych badań stosowanych. Przy ich wyszczególnianiu można brać pod uwagę wykorzystywane $\mathrm{w}$ interwencjach narzędzia badawcze (podobnie jak Claudia Mitchell; 2008), dyscypliny akademickie, które je wypracowują, bądź obszary, na których są one stosowane (co proponuje Pink; 2009). Można jednak wyjść też od statusu i roli, jakie przypisuje się obrazom w tych interwencjach, tłumacząc zasady ich funkcjonowania na reprezentatywnym przykładzie. Zaletą takiego podejścia pozostaje możliwość późniejszego przenoszenia wyszczególnionych strategii pomiędzy różnymi obszarami interwencji, przy jednoczesnym artykułowaniu sygnalizowanych wyżej przemian. Spróbujmy podążyć tym tropem.

\section{Obraz jako rzecznik}

W 1985 roku Monica Frota, fotograf i filmowiec, wraz z dwójką zaprzyjaźnionych antropologów, rozpoczęła w Brazylii projekt „Mekaron Opoi D’joi” 
(w języku Kayapo: ten, który tworzy obrazy) ${ }^{7}$. Przez dwa lata współpracowali z dwiema grupami Kayapo: Metuktire i Mekrangnotami, wypożyczając im sprzęt wideo i towarzysząc $\mathrm{w}$ procesie rejestrowania. Zapał, $\mathrm{z}$ jakim Kayapo zabrali się do filmowania, a także to, jak szybko przestali dokumentować swoje zanikające rytuały i zaczęli używać medium do działań mających ich bronić przed procesami industrializacji, odpowiadały występującemu w ich kulturze podejściu do przedstawień - symbole nie miały świata reprezentować, ale tworzyć go wedle określonych zasad. Kayapo rejestrowali porozumienia podpisywane $z$ rządem (nikt nie mógł potem twierdzić, że do nich nie doszło) i swoje protesty przed pałacem prezydenckim. Wizerunek Indian z kamerami wideo szybko zaciekawił media, co dało Kayapo nagłośnienie ich postulatów, w tym okładkę jednego z numerów „Timesa”, który zamieścił materiał poświęcony temu, jak sprzeciwili się rządowym planom budowy tamy grożącej zatopieniem ich ziem. Kayapo, wyposażeni w kamery i ponadnarodowe zainteresowanie sprawą (również po wyjeździe antropologów), protestując, lobbując w kręgach polityki i władzy, współpracując z międzynarodowym ruchem na rzecz obrony praw człowieka i ochrony środowiska, wywalczyli sobie polityczne i finansowe wsparcie oraz rządowe gwarancje ich praw do kontrolowania swojej ziemi i zasobów, które ona skrywa.

Dziesięć lat po rozpoczęciu projektu „Mekaron Opoi D’joi”, w zupełnie innej części świata, Gillian Caldwell spotkała się ze znajomym, który zgłębiał problem nielegalnego handlu tygrysimi skórami na Syberii (zob. Caldwell 2005, s. 1-19). Podczas jednej z rozmów handlarz zaproponował temu dziennikarzowi kupno kobiet. Caldwell, radca do spraw ochrony praw obywatelskich, niezależnie od braku doświadczenia $\mathrm{w}$ temacie, a także materii filmu, nie potrzebowała wiele czasu do namysłu. Po dwóch latach prac powstał dokument Bought \& Sold: An Investigate Documentary About the International Trade in Women. Złożyły się nań materiały zarejstrowane mikrokamerą podczas spotkań $z$ handlarzami, rozmowy z kobietami zmuszanymi do prostytucji oraz fachowcami zajmującymi się tym zjawiskiem na całym świecie. Połączenie specjalistycznych analiz $z$ bezpośrednimi relacjami uprowadzonych kobiet oraz szeroka współpraca $z$ osobami i organizacjami zajmującymi się problemem prostytucji sprawiły, że film zyskał międzynarodowy rozgłos, przywołując temat nieco wówczas w Stanach Zjednoczonych zapomniany. Nie był to jednak jego jedyny rezultat. Autorów zaproszono do współpracy przy formowaniu pierwszej rządowej grupy do spraw przemytu ludzi, uczestniczyli oni również w pracach nad Trafficking Victims Protection Act (dokument przyjęty przez Kongres w roku 2000).

Interwencyjny potencjał „Mekaron Opoi D'joi” i Bought \& Sold był oparty na wykorzystaniu obrazu w roli „rzecznika”. Jego celem było dokumentowa-

7 Przedstawiam ten projekt opierając się w głównej mierze na opisie, który znalazł się w pracy Making Waves: Stories of Participatory Communication for Social Change. A report to the Rockefeller Foundation (Dagron 2001, s. 64-76), a także na artykule Terence'a Turnera (1992). 
nie, a następnie upublicznianie określonych wydarzeń, procesów i stanów żeby $\mathrm{w}$ ten sposób zwrócić uwagę na wiążące się z nimi problemy i w dalszej kolejności sprowokować proces zmian, angażujący pozafotograficzne środki. Rzecznictwo to od klasycznego fotoreportażu (np. socjologizujący Jakob Riis czy Lewis Hine) odróżnia przyznawany obrazowi status - w większej niż dawniej mierze czyni się użytki z jego subiektywnego i refleksyjnego wymiaru; nierzadko czerpiąc inspiracje z krytyki, której antropologia poddała samą siebie w latach siedemdziesiątych XX wieku. Przekazanie w ręce Kayapo kamer, a wraz z nimi odpowiedzialności za własny wizerunek, odwołuje się do wyrastającej z tej krytyki tradycji filmowej, do obrazów Jeana Roucha (2003 [1973]) czy „kina opartego na współpracy” Davida MacDougalla (1975, za: Pink 2006, s. 90), próbujących zerwać z niechlubnym obyczajem pierwszych filmów etnograficznych, w których obiektywizujące oko kamery portretowało „obcych”, nie uwzględniając swoistości lokalnych kultur, reprodukując za to kolonialny układ zależności (por. Edwards 1992). Wobec braku roszczeń co do prymarności jakiejkolwiek perspektywy, obrazy orędują dziś przeciwko tej właściwości, którą im niegdyś przypisywano i której zawdzięczały swoje interwencyjne potencje obiektywizmowi. Kwestionując same siebie, realizują jednocześnie cele, które stawiał etnosocjologii Pierre Bourdieu: „odnaturalizowanie i odfatalizowanie egzystencji poprzez zaangażowanie swoich kompetencji w służbie uniwersalizmowi zakorzenionemu w rozumieniu partykularyzmów" (za: Burawoy 2010, s. 555).

Tak zdefiniowane rzecznictwo można również łączyć z „mediami alternatywnymi" (zob. np. Harding 1997; Waltz 2005). Coraz większa koncentracja masowych mediów w rękach prywatnych inwestorów, którzy wobec braku państwowych dotacji muszą szukać wsparcia u reklamodawców, nakłada na nich określone wymagania co do treści. Jeśli dodać do tego niechęć mediów publicznych do podejmowania pewnych tematów ze względów politycznych, to okaże się, że niełatwo jest zainteresować media czy skłonić je do współpracy przy projektach takich jak powyższe. Media masowe, choć często sprawiają wrażenie tworzenia przestrzeni debaty publicznej, ustanawiają warunki zmieniające strukturę tej debaty tak, że jej uczestnicy mają nierówne pozycje w dialogu (Habermas 2008). Współczesna specyfika obrazów jako rzeczników polegałaby więc i na tym, że w odróżnieniu od swoich protoplastów, dzięki możliwościom nowych technologii, wykorzystywane są one poza mediami głównego nurtu i dostarczają alternatywnych przestrzeni debaty nad problemami społecznymi. Żeby nie popaść w kolejną pułapkę kolonialnej antropologii, dodajmy i to, że obrazy służą dziś orędowaniu na rzecz „obcych”, którzy niekoniecznie mieszkają oddaleni o tysiące kilometrów. Przykładem - projekt „Świat. Fotografie dzieci z Jasionki i Krzywej" fotografa Piotra Janowskiego (2002). Niekoniecznie muszą być oni również powszechnie postrzegani jako zmarginalizowani. Przekonują o tym skandynawskie studia nad designem, w których oręduje się za interesem docelowych użytkowników projektowanych technologii (Ehn 1992). 


\section{Obraz jako pośrednik kulturowy}

Planujący terapię lekarze dysponują ograniczonym wyobrażeniem o warunkującym chorobę psychologicznym, społecznym i materialnym środowisku pacjenta. Choć stosuje się na przykład wywiad lekarski specjalnie przygotowany dla zachorowań na astmę, młodzi astmatycy nie zawsze chcą i mogą podzielić się informacjami na ten temat, albowiem często, na poziomie dyskursywnym, po prostu nie zdają sobie $z$ nich sprawy i nie potrafią ich zrelacjonować. W 1994 r., w bostońskiej klinice zdrowia dziecka, we współpracy z antropologami, rozpoczęto projekt, który miał wypełnić tę lukę: „Video Intervention/Prevention Assessment" (Chalfen, Rich 1999) ${ }^{8}$. Pacjentom rozdano kamery wideo, prosząc, by dokumentowali swoje życie z chorobą - nagrywali na taśmie swoje domy, szkoły, gabinety lekarskie oraz inne miejsca, w których bywaja; przeprowadzali rejestrowane wywiady z członkami rodziny i przyjaciółmi na temat swojej choroby i jej społecznych konsekwencji, a także rejestrowali osobiste monologi, poświęcone przeżyciom, aktualnym wydarzeniom i doświadczeniom choroby. Efektem tych działań były narracje wizualne, przeglądane wspólnie przez lekarzy i pacjentów, a następnie poddane analizie w interdyscyplinarnym gronie antropologów, socjologów, lekarzy i psychologów. Sportretowany przez młodych pacjentów obraz własnej choroby daleko odbiegał od tego, do czego przyzwyczaili się lekarze; uzyskano wiedzę, której nie oferowały poprzednie badania. Wgląd w codzienne doświadczenia astmy i w jej przebieg w „naturalnych” warunkach umożliwił przeprojektowanie terapii na bardziej efektywną oraz posłużył jako materiał instruktażowy dla studentów medycyny.

Richard Chalfen i Michael Rich czerpią w głównej mierze z pionierskich badań nad Indianami Nawajo (inspirowanych hipotezą Sapira-Whorfa), realizowanych przez Johna Adaira i Sola Wortha pod koniec lat sześćdziesiątych (1997[1972]). Badania te zapoczątkowały także lawinę innych projektów ${ }^{9}$, opartych na tych samych dwóch podstawowych założeniach. Po pierwsze, rozdanie badanym kamer/aparatów oferuje wgląd w sposób postrzegania przez nich świata, a tym samym również $\mathrm{w}$ to, jak ów świat jest przez nich doświadczany i konstruowany. Po drugie, wideo ułatwia interesubiektywizację perspektywy badanych dzięki materiałowi wyzwalającemu dyskusje na tematy, które trudno byłoby sprowokować; zwłaszcza gdy badanymi są osoby o niskiej kompetencji językowej. Wideo pełni wówczas rolę swoistego „pośrednika kulturowego" (Chambers 1985), umożliwiając interwencję opartą na transferze wiedzy między przedstawicielami odmiennych światów społecznych, cho-

8 Więcej informacji na temat rozwoju metodologii VIA, w tym również o próbach jej wykorzystania w innych niż astma chorobach zob. Chalfen, Rich 2004.

$9 \mathrm{~W}$ polskim kontekście zob. np. poświęcony wyobraźni społecznej projekt Rafała Drozdowskiego i Marka Krajewskiego (2008). 
ciażby lekarzy i i ich pacjentów. Istotnym zadaniem obrazów nie jest zatem $\mathrm{w}$ tym przypadku wiarygodne relacjonowanie rzeczywistości, ale ich funkcja jako medium komunikacji (Clark-Ibáñez 2004, s. 1512).

W zupełnie innym kontekście, ale w podobny sposób wykorzystywała wideo Sarah Pink. W latach 1999-2000 na zlecenie firmy Unilever Consumer Science prowadziła projekt „Cleaning, Home and Lifestyles”. Jego celem był opis multisensorycznego doświadczania domu, ze szczególnym uwzględniem czynności $\mathrm{z}$ użyciem produktów, które znajdują się w ofercie firmy: kosmetyki do higieny osobistej oraz środki czystości (Pink 2004, s. 20-40; zob. też. Pink 2006, s. 59$-69,94-96)$. Pink prosiła respondentki, by z kamerą w ręku oprowadziły ją po swoim mieszkaniu i pokazały miejsca, w których zazwyczaj podejmują czynności związane $z$ higienią osobistą i sprzątaniem, rejestrując, $w$ jaki sposób je wykonują. Przeprowadzone zostały również wywiady jakościowe.

Badaczka starała się $\mathrm{w}$ ten sposób dotrzeć do pozadyskursywnej wiedzy zarządzającej dbaniem o czystość, w tym do tych jej wymiarów, które zazwyczaj pozostają poza zasięgiem standardowych narzędzi badawczych: doświadczeń węchowych, taktylnych oraz słuchowych. Wideo umożliwiło dostęp do informacji, które są obecnie wykorzystywane przy projektowaniu produktów oraz strategii marketingowych Unilever; ujawniło swoją kolejną funkcję w ramach kulturowego pośrednictwa - możliwość podzielania wiedzy o charakterze nie tyle symbolicznym, ile wcielonym i urzeczowionym. Co istotne, poza oferowaną badaczowi możliwością obserwowania wiedzy w działaniu, konsekwencją tej formy pośrednictwa jest również urefleksyjnienie tej pozadyskursywnej wiedzy przez samych badanych, co umożliwia istotne pogłębienie jej rozumienia w toku wspólnej rozmowy. $Z$ tego właśnie powodu wideo wykorzystywane jest współcześnie w badaniach nad środowiskami pracy, zwłaszcza jeśli sposób interagowania $z$ interfejsami/obiektami materialnymi wyznacza ich zasadniczą specyfikę, jak w przypadku kontrolerów ruchu lotniczego czy dyspozytorów karetek (Heath, Knoblauch, Luff 2000) lub operatorów procesów chemicznych w oczyszczalniach ścieków (Sperschneider 2007).

\section{Obraz jako animator}

Po jednej ze swoich wystaw w galerii w brukselskiej dzielnicy Anneessens rzeźbiarka El Dietvorst zdecydowała się na spacer po okolicy. Organizatorzy starali się ją odwieść od tego pomysłu ${ }^{10}$. Ostrzegali ją przed wysokim wskaźnikiem przestępczości, wandalizmem i narkomanią — dzielnicę zamieszkiwali głównie tworzący zamknięte enklawy bezrobotni imigranci, którym brakowało wspólnego celu. Dietvorst opuszcza jednak mury galerii, zafascynowana miejscem i jego mieszkańcami organizuje casting do filmu. Ma to być fabuła, ale

10 Opisując przebieg działania Dietvorst korzystam z opracowania etnografki projektu An van Dienderen (2007). 
w dużym stopniu oparta na doświadczeniach okolicznych mieszkańców. Co istotne, realizowana przy ich znacznym współudziale. Casting, na który przychodzi dwieście osób, staje się początkiem czteroletniego projektu, wspieranego przez belgijski rząd oraz kilka organizacji pożytku publicznego. W skład zespołu pracującego nad filmem, poza artystką i kilkoma jej znajomymi, wchodzą ludzie bez prawa stałego pobytu, prostytutki, emigranci z różych stron świata, a także projektant oprogramowania oraz policjant. Artystce udaje się ich wszystkich przekonać, że wspólnie mają coś istotnego do powiedzenia wszyscy razem piszą scenariusz. Mieszkańcy Anneessens występują w filmie w rolach, które sami dla siebie napisali (będących w większości projekcją wymarzonych zawodów). Kanwą opowieści są różnice kulturowe. The March, The Burden, The Desert, The Boredom, The Anger ma swoją premierę w jednym z najbardziej prominentnych kin Brukseli.

Rezultaty projektu sięgają zdecydowanie dalej. Kilkoro uczestników produkcji znajduje pracę. Inni, zainspirowani więziotwórczą potencją medium, działają na rzecz integracji lokalnej społeczności. Anneessens na mapie Brukseli pojawia się już nie tylko w kontekście wysokiego bezrobocia i przestępczości, ale jako miejsce bogate w inicjatywy kulturalne. Wyłania się przestrzeń publiczna. Rozpoznawszy pozaikoniczne potencje obrazów, Dietvorst wykorzystała medium filmowe jako pretekst do integracji lokalnej społeczności, opierając się na kolektywnym współdziałaniu, partnerskim dialogu oraz sprowokowanych pracą nad filmem interakcjach między ludźmi, których wcześniej łączyło niewiele bądź nic. Odpowiednio dobrana tematyka projektu zachęcała do negocjowania nie tylko różnych pomysłów na film, ale i dzielenia się swoimi życiowymi doświadczeniami, marzeniami i zwyczajami. W kontekście prób wytworzenia przestrzeni wspólnej debaty proces filmowania okazał się istotniejszy niż produkt. Aktywny udział w projekcie zmienił uczestniczących w nim, włączając w obręb społeczeństwa, socjalizując przez sztukę, dając hobby, reorganizując tożsamość grupową i jednostkową. Filmowanie oparte na współpracy, tak różne od powszechnego doświadczania bycia przedmiotem czyjejś oceny, przeniosło ciężar odpowiedzialności na lokalnych mieszkańców, emancypując ich i przywracając im wiarę we własną sprawczość.

Obraz w roli „animatora” ma zmieniać rzeczywistość nie przez jej przedstawianie, ale przez praktyki fotografowania, które jej towarzyszą. W sposób najbardziej dosłowny obserwowaliśmy tę jego funkcję w działaniach Dietvorst, ale korzystali z niej również Chalfen i Richa (1997, 2004) oraz Monica Frota i Terence Turner (1992). W przypadku „Video Intervention/Prevention Assessment" w poprawie zdrowia młodych astmatyków tak samo istotne jak wiedza, w której transferze pomagały obrazy, okazały się ich „usamowolniające” potencje. Przekazanie kontroli nad narracją o chorobie w ręce młodych pacjentów u części z nich wywołało przeświadczenie, że z równie dobrym skutkiem mogą zarządzać swoją chorobą, a uwzględnienie przeżyć w terapii przekonało ich, że ich doświadczenia mają konkretne przełożenie na podejmowane przez leka- 
rzy decyzje (Chalfen, Rich 1999). Dla Kayapo możliwość rejestrowania i montażu materiałów wizualnych oznaczała przyjęcie w społeczności prestiżowej roli politycznej odpowiedzialności za mediowanie ze światem zachodnim (Turner 1992, s. 7). Obiektyw kamery, pełniąc rolę znaczące go in nego, dostrzegł Kayapo w tej roli, co sprawiło, że i oni się z nią utożsamili.

\section{Obraz jako indagowany}

Nie dajcie się zwieść oczywistości przedstawień wizualnych! Zdystansujcie się od pozorów, które podpowiada oko i przyjrzyjcie się im dokładnie. Krytyka obrazów technicznych, zrywając z potocznym utożsamianiem reprezentacji z tym, do czego odsyła, przynajmniej od czasów Siegfrieda Kracauera (2010), realizowała swoje cele w ramach społecznych studiów nad obrazem. Przybrała na sile wraz $z$ upowszechnieniem mediów masowych i kultury popularnej i zachęcała do traktowania obrazów jako odbicia ideologicznych warunków, które doprowadziły do ich powstania, proponując kategorie w rodzaju "męskiego" czy „kolonialnego” spojrzenia. Skłaniała do zwracania uwagi na dyskursy reprodukujące nierówny układ zależności, który naturalizowały za pomocą obiektywizującego statusu medium, czyniąc w ten sposób swoją ka pila rną władzę jeszcze bardziej efektywną.

Na tym właśnie planie można rozpatrywać krytyczną refleksję Rolanda Barthes'a (2009), dopatrującego się w klasycznej analizie reklamy Panzani tego, w jaki sposób jej symbolika zachęca konsumenta do nabycia sosu do spaghetti przez jego odniesienie do idei domowego jedzenia i „włoskości”, albo szukającego $\mathrm{w}$ przedstawieniu czarnoskórego żołnierza salutującego pod francuską flagą próby zalegitymizowania kolonialnej polityki Republiki. Podobne cele odnajdziemy u Johna Bergera (2009), odnotowującego w fotografiach obecne od dawna reguły przedstawiania kobiet jako przedmiotu podległego męskiemu spojrzeniu. W tym samym kontekście czytać można również pracę Catherine Lutz i Jane Collins (1993), monitorującą sposób w jaki portretuje się nie-zachodnie kultury w czasopiśmie „National Geographic".

W rozwoju tego typu refleksji dostrzegamy jednak charakterystyczny zwrot. Upowszechnieniu założeń poststrukturalizmu w obrębie krytycznej analizy przedstawień towarzyszy coraz silniejsze odejście od definiowania obrazu w kategoriach obiektywności/przekłamania (zob. np. Tagg 2009). Pora kończyć poszukiwanie prawdziwie wiarygodnych reprezentacji technicznych, albowiem na tym właśnie polega ich społeczne życie, że towarzyszą im rozmaite dyskursy, realizujące partykularne cele. Innymi słowy, nie istnieje przestrzeń wolna od ideologii, a jedyne, co możemy w tej sprawie zrobić, to uczulać na tę właśnie specyfikę obrazów, zachęcając jednocześnie każdego z osobna, żeby traktował je na tej samej zasadzie jak słowa: uznając ich gramatykę. Przekonali się do tego dyrektorzy szkół z hrabstwa Durkham, 
kiedy w roku 1990, zachęceni rezultatami zeszłorocznych warsztatów, zaprosili fotograf Wendy Ewald do uczestnictwa w projekcie „Kształcenie poprzez fotografię” („Literacy Through Photography”). Fotoesej, albumy rodzinne, wystawy i samodzielne fotografowanie wykorzystano $\mathrm{w}$ dydaktyce szkolnej.

Uczniowie zaczęli od autoportretów, a potem robili zdjęcia swoim rodzinom, miejscom, w których bywają, a na końcu przeżyciom i marzeniom ${ }^{11}$. Tematy stawały się coraz bardziej ogólne. Dzieci stopniowo uczyły się wykorzystywać medium do coraz bardziej ekspresyjnych relacji o kształcie własnego świata, takiego, jakim go widzą i jakim chciałyby go uczynić. Biegłość w fotografowaniu zaczęła się przekładać na rosnące zdolności pisarskie, gdy Ewald prosiła dzieci, aby zaopatrywały swoje zdjęcia w werbalne opisy doświadczeń, które się z nimi łączą. Umiejętności, które starała się wyuczyć szkoła na innych przedmiotach, zaczęły być wykorzystywane i rozwijane w osobistych narracjach towarzyszących fotografowaniu, rozmowach o zdjęciach, nadawaniu im tytułów oraz planowaniu wystawy. Obrazy techniczne stały się plastyczne, bierne narzędzie okazało się kreatywnym medium ekspresji. Robienie i układanie zdjęć w opowieści ujawniło subiektywny charakter. Fotografia na oczach dzieci zmieniała swój status — od neutralnej techniki obserwacji do pojemnego narzędzia twórczych wypowiedzi.

Warsztaty w Durkham trwają od dziesięciu lat. Obraz pełni w nich rolę „indagowanego”. Służy jako „worek treningowy”. Jego analiza ma za zadanie nie dotarcie do tego, co „za oknem”, ale skłonienie do patrzenia „na” i „za” obraz (Wright 1999, s. 36-68), a więc do śledzenia tego, w jaki sposób reprezentacje przenoszą swoje komunikaty, oraz do obserwacji przygodnych reguł kulturowych, które powołały owe zasady do życia i które obrazy pomagają upowszechnić. Indagowany obraz interweniuje, uczulając na swoją rolę i ucząc, jak się nim posłużyć do własnych celów. Co istotne, jak pokazuje projekt Ewald, obraz pełni dziś tę funkcję również na zewnątrz akademii. Wykracza także poza biura projektantów i ewaluatorów kampanii reklamowych. Dociera do szkół podstawowych, i to nie jako refleksja nad rolą kultury wizualnej w procesach edukacji (zob. Pater-Ejgierd 2010), ale w formie poświęcanych jej zajęć dydaktycznych. Jego rola odpowiada również współczesnemu pojmowaniu kompetencji wizualnej, opartemu na poszerzonej koncepcji obrazu (por. Rogowski 2010). Uwzględnienia domaga się nie tylko umiejętność odczytania obrazu, ale i kompetencje techniczne niezbędne do wytwarzania własnych przekazów, a także zdolność dostrzegania mechanizmów reprodukowania nierówności zdeponowanych za obrazami: między innymi $\mathrm{w}$ obyczajach i technikach ich wykonywania oraz posługiwania się nimi.

11 Opis projektu za: http://www.dukemagazine.duke.edu/dukemag/issues/111206/depgaz9. html oraz: http://cds.aas.duke.edu/exhibits/past/ltp10/front.html [18.01.2011]. 


\section{Obraz jako dozorca}

W dniu 27 marca 2009 r. na paryskich przedmieściach Saint-Ouen niebo nad dokami rozświetlił zielony snop dymu. Do akcji ruszyli miejscowi strażacy, ale nie znaleźli niczego, co mogliby ugasić. Zestaw umieszczonych na pobliskich budynkach inteligentnych projektorów jaskrawo rysował kontur w zależności od ilości zanieczyszczeń utylizowanych $\mathrm{w}$ tym czasie $\mathrm{w}$ spalarni ${ }^{12}$. Po tygodniach planowania i sporów z lokalnymi władzami dwoje artystów w prosty i efektowny sposób zrealizowało swój cel - zwrócili uwagę społeczności na problem zanieczyszczania środowiska i jej bezpośredni wpływ na jego skalę. Zagrożenie, niebezpieczne tym bardziej wobec braku widzialnej reprezentacji, uobecniło się w świadomości mieszkańców i skłoniło władze do ponownego rozpatrzenia problemu.

Projekt „The Green Cloud” można potraktować jako ilustrację perspektyw wyłaniających się przed badaniami stosowanymi po przyjęciu założenia o sprawczej roli materialności w życiu społecznym. Ich oddziaływanie, równie dobrze jak na zmianę postaw, może być obliczone na zmianę/urefleksyjnienie technologii, którymi posługujemy się na co dzień. Do takiego sposobu myślenia zachęca między innymi Bruno Latour (2009), argumentując, że efektywna interwencja dokonywana z pola nauk społecznych musi przekraczać granice historycznie przeznaczanej dla nich problematyki (bazujące na oddzieleniu tego, co społeczne, od tego, co materialne; zob. też Latour 2011). Jego zdaniem, możliwa jest ona dziś o tyle, o ile będzie wymierzona nie w społeczności, ale w „kolektywy”, a więc będzie uwzględniać sieci relacji, które wiążą ludzkich i nie ludzkich aktorów społecznych. Żadne przeszkody nie staną już wówczas badaczom na drodze do aktywnego zaangażowania się $\mathrm{w}$ proces projektowania nowych „dozorców” - wizualizacji, na które delegujemy obowiązki czuwania nad naszym bezpieczeństwem i wartościami, wtedy gdy sami nie mamy na to czasu bądź gdy nasze oczy nie są w stanie dostrzec ryzyka. W warunkach nieprzejrzystej późnej nowoczesności (Giddens 2001) dozorcy wyręczają nasze sumienie, sygnalizując moment, w którym reakcja ludzka okazuje się niezbędna.

Technologie obrazów-dozorców niekoniecznie muszą być przy tym skomplikowane. Także ryzyko, które domaga się ich kontroli, może się wymykać mniej naszym zmysłom, a bardziej sposobom myślenia. Kumulujące się od dawna zagrożenia pozostają bowiem dla aktorów społecznych niewidzialne nie dlatego, że są niewidoczne (jak dwutlenek węgla i metale ciężkie w powietrzu czy bakterie w wodzie), ale ponieważ uznają je oni za naturalne, swoiste dla okresu, w którym żyją. Herald Welzer tłumaczy to zjawisko, posiłkując się

\footnotetext{
12 Opis projektu za: http://hehe.org2.free.fr/?page_id=121\&language=fr [16.01.2011], pierwsze zdanie relacji nawiązuje stylistyką do poświęconego mu artykułu Le rayon vert divise Saint-Quen autorstwa Marie Lechner, opublikowanego 3 czerwca 2009 r. na stronach „Le Libération” (http://www.liberation.fr/culture/0101570790-le-rayon-vert-divise-saint-ouen [18.01.2010]).
} 
kategoriami psychologii środowiskowej - zmieniające się punkty odniesienia (shifting baselines) sprawiają, że za naturalny „ludzie uważają taki stan środowiska, który zbiega się z czasem ich życia i doświadczenia" (Welzer 2010, s. 176). Na przykład młodzi rybacy nie dostrzegają procesu wymierania ryb na skutek zanieczyszczeń wody, ponieważ pewnych gatunków nigdy nie łowili (Welzer 2010, s. 177-178). Wiele problemów społecznych daje się wyjaśnić na podobnej zasadzie. Wiele użytków czyni się dziś z obrazów w celu poszerzenia perspektywy. Rolę dozorcy może pełnić choćby refotografia, która powtarzając kadry $\mathrm{w}$ równych odstępach czasu, portretuje przemiany wykraczające poza ramy codziennego postrzegania (por. np. Rieger 1996, 2003).

\section{ROZŁOŻYĆ I Z POWROTEM ZŁOŻYĆ}

Przemiany sposobu definiowania organizacji społecznej i obrazu na użytek nauk społecznych, a także rosnąca dostępność technologii wytwarzania i upowszechniania obrazów, istotnie zaważyły na charakterystyce dzisiejszych wizualnych badań stosowanych. Ściśle wiążą się one z porażką określonych projektów politycznych, które wbrew prorokowanemu końcowi historii nie tylko nie dostarczyły rozwiązania zastanych problemów społecznych, ale i przysporzyły nowych. Obrazy pomagają dziś nie tyle budować modernistyczny projekt, ile uporać się z jego konsekwencjami: problemy wywołane migracjami, kolonizacją, nadmierną eksploatacją środowiska naturalnego, przeniesieniem produkcji przemysłowej do krajów Trzeciego Świata, postępującym zanikiem tożsamości lokalnych, prywatyzowaniem przestrzeni publicznych i tak dalej. Doskonale wpisują się również w tendencję cechującą współczesną kulturę - przejście od nowoczesnej utopii planowanego postępu do ponowoczesnej utopii partycypacji ${ }^{13}$.

Przekraczaniu idei, które kiedyś zdawały się oczywiste, towarzyszy nie tylko przekraczanie granic teorii i praktyki (podkreśla się wręcz ich jedność - zmiana rzeczywistości jest częścią badania; Gliński 1980, s. 134-135), ale i przekraczanie granic w obrębie samej akademii. Podobnie jak ich uniwersytecki odpowiednik, współczesne wizualne badania stosowane bogactwo rezultatów zawdzięczają łączeniu rozważań socjologii, antropologii i studiów kulturowych z doświadczeniami animacji kulturowej, sztuki publicznej, studiów nad projektowaniem, fotoreportażu (tradycja dialogu), historii sztuki, filozoficznej krytyki kultury i pedagogiki. Porównując ze sobą choćby te pierwsze (zob. np. Godlewski 2008; Kwon 2004; Sanders, Stappers 2008; Rouillé 2007, s. 204-212) szybko przekonamy się, ile interwencje wizualne zyskują i ile jeszcze mają do zyskania w rezultacie takiej współpracy.

\footnotetext{
${ }^{13} \mathrm{~W}$ kategoriach politycznych, ale również według coraz popularniejszych w socjologii orientacji (przynajmniej od czasów Millsa; 2008) cele i ścieżki własnego rozwoju powinno wyznaczać samo społeczeństwo.
} 
Do współdziałania może przekonać również popularność, którą współczesne wizualne badania stosowane zyskują na rozmaitych obszarach praktyki: $\mathrm{w}$ instytucjach publicznych (głównie w szkolnictwie i sektorze ochrony zdrowia, ale i bezpieczeństwie narodowym), wspólnotach lokalnych oraz w przemyśle (między innymi jako antropologia designu oraz etnografia konsumpcji). $\mathrm{Z}$ ich zalet korzysta się na rozmaitych etapach projektu: od rekonstrukcji problemu, poprzez budowę rozwiązań, ich wdrażanie i ewaluację, aż do komunikowania wyników. Realizowanie celów pozaakademickich kojarzy badania stosowane z koniecznością uwzględnienia określonych problemów czasowych, finansowych, etycznych i komunikacyjnych, a także innych ograniczeń, na które zwraca uwagę Krzysztof Frysztacki (1996). Często wiąże się również z tą ich specyfiką, że bardziej niż celom poznawczym mają służyć rozwiązaniu problemów, z którymi mierzy się zleceniodawca. Nie oznacza to wcale, że wizualne badania stosowane nie mogą wnieść istotnego wkładu w refleksję akademicką (chociażby ewaluując wypracowywane metodologie w nowych kontekstach zastosowań). Rozwijanie tej oraz innych potencji zdecydowanie wymaga jednak dalszej krytycznej refleksji.

Refleksję taką należy rozpocząć od podstaw. Jak starałem się pokazać, współczesne badania wizualne mogą pełnić swoje role dzięki znacznemu pogłębieniu relacji między wizualnością a projektem zmiany. Wystarczy porównać, $\mathrm{w}$ jaki sposób fotografią posługiwała się Johnston, z użytkami, które czyniła z niej Ewald. Przejście od narzędzia reprezentacji do wehikułu modyfikowania relacji społecznych otwiera dla obrazów zupełnie nowe pola zastosowań - korzysta się z nich dzisiaj niekoniecznie dla ich właściwości ikonicznych, ale także dla emancypacyjnych zalet procesu ich wytwarzania oraz więziotwórczych potencji sytuacji społecznych, do których mogą prowokować. Dzięki temu obrazy mogą być nie tylko rzecznikiem, ale też pośrednikiem kulturowym, animatorem lokalnych społeczności, pomagać w edukowaniu kompetencji wizualnej czy kontrolować za nas środowisko naszego życia. Co więcej, jak się o tym przekonaliśmy na przykładzie projektu „Video Intervention/Prevention Assessment”, role te wcale się nie wykluczają, wręcz odwrotnie - powszechną praktyką jest ich łączenie.

Fotografia i wideo przyjmują różne tożsamości, ponieważ - inaczej niż się o nich powszechnie sądzi i na czym opiera się większość ich interwencyjnych zastosowań — nie mają swojej własnej. Nie gwarantują jej ani technologia zapisu, ani dyskurs. Wbrew temu, co mogą sugerować tytuły omówionych strategii, obraz nie ma zatem żadnych własności czy ról, ale jest nimi każdorazowo wypełniany w konkretnych sieciach relacji. Powodów skuteczności opisanych wyżej projektów należy zatem poszukiwać poza samymi obrazami. Na przykład procesy dekolonizacji Kayapo, paradoksalnie, zostały uruchomione przez spojrzenie kolonialne - bardziej niż obrazy, które Kayapo tworzyli, zaciekawił zachodnie oko obraz samych Kayapo $z$ kamerami wideo na ramieniu, tak różny od powszechnego wizerunku „pierwotnych” społeczności. Z podobną sytuacją 
mieliśmy do czynienia w przypadku fotografii dzieci z Jasionki i Krzywej, dla których tubą stała się nie tylko fotografia, ale i znany fotograf, pracujący w potężnej instytucji medialnej (Janowski, Kula, Noniewicz 2002). Sygnalizowane strategie należy zatem traktować jedynie jako potencje. W istocie skuteczność interwencji, podobnie jak status obrazu, zależy od dużo dłuższej listy elementów. Musimy nauczyć się je dostrzegać, śledzić i oceniać, czyli - parafrazując Latoura - rozkładać interwencje wizualne na części i ponownie je składać wedle czytelnych i sprawdzonych reguł, do czego niniejsze rozważania stanowią — mam nadzieję — zachętę.

\section{BIBLIOGRAFIA}

Abriszewski Krzysztof, 2008, Poznanie, zbiorowość, polityka. Analiza teorii aktora-sieci Bruno Latoura, Universitas, Kraków.

Adair John, Worth Sol, Chalfen Richard, 1997, Through Navajo Eyes: An Exploration in Film Communication and Anthropology, University of New Mexico Press, Albuquerque.

Barthes Roland, 2009, Mitologie, tłum. Adam Dziadek, Aletheia, Warszawa.

Bateson Gregory, 1980, An Analysis of the Nazi Film “Hitlerjunge Quex”, „Studies in Visual Communication", t. 6, nr 3, s. 20-55.

Benedict Ruth, 1999, Wzory kultury, tłum. Jerzy Prokopiuk, Muza, Warszawa.

Berger John, 2009, Sposoby widzenia, tłum. Mariusz Bryl, Aletheia, Warszawa.

Berger Peter L., Luckmann Thomas, 2010, Społeczne tworzenie rzeczywistości. Traktat z socjologii wiedzy, tłum. Józef Niżnik, Wydawnictwo Naukowe PWN, Warszawa.

Burawoy Michael, 2010, O socjologię publiczna. Wystapienie prezydenckie z roku 2004, thum. Agata Dziuban, w: Aleksander Manterys, Janusz Mucha (red.), Nowe perspektywy teorii socjologicznej. Wybór tekstów, Nomos, Kraków.

Caldwell Gillian, 2005, Using Video for Advocacy, w: Sam Gregory, Gillian Caldwell, Ronit Avni, Thomas Harding (red.), Video for Change: A Guide for Advocacy and Activism, Pluto Press, London.

Chalfen Richard, Haley Jay, 1971, Reaction to Socio-documentary Film Research in a Mental Health Clinic, „American Journal of Orthopsychiatry”, t. 41, s. 91-100.

Chalfen Richard, Rich Michael, 1999, Showing and Telling Asthma: Children Teaching Physicians with Visual Narrative, „Visual Sociology”, t. 14, s. 51-71.

Chalfen Richard, Rich Michael, 2004, Applying Visual Research: Patients Teaching Physicians about Asthma through Visual Illness Narratives, „Visual Anthropology Review”, t. 20, s. 17-30.

Chambers Erve, 1985, Applied Anthropology: A Practical Guide, Prentice Hall, Englewood Clifs.

Clark-Ibáñez Marisol, 2004, Framing the Social World with Photo-Elicitation Interviews, „American Behavioral Scientist”, t. 47, s. 1507-1527.

Collier John, 1986, Visual Anthropology: Photography as a Research Method, University of New Mexico Press, Albuquerque.

Collier John, 1973, Alaskan Eskimo Education, Holt, Rinehart \& Winston, New York.

Dagron Alfonsio G., 2001, Making Waves: Stories of Participatory Communication for Social Change. A Report to the Rockefeller Foundation, The Rockefeller Foundation, New York. 
De Lange Nayden, Mitchell Claudia, Stuart Jean (red.), 2007, Putting People into Picture: Visual Methodologies for Social Change, Sense, Amsterdam.

Drozdowski, Rafał, Krajewski Marek (red.), 2008, Wyobraźnia społeczna. Horyzonty —źródła - dynamika. Uwarunkowania strategii dostosowawczych wspótczesnego społeczeństwa polskiego - studium socjologiczne, Wydawnictwo Naukowe UAM, Poznań.

Drozdowski Rafał, Krajewski Marek, 2010, Za fotografie. W strone radykalnego programu socjologii wizualnej, Fundacja Bęc Zmiana!, Warszawa.

Edwards Elizabeth (red.), 1992, Anthropology E Photography 1860-1920, Yale University Press, New Haven-London.

Edwards Elizabeth, Hart Janice, 2004, Introduction: Photographs as Objects, w: Elizabeth Edwards, Janice Hart (red.), Photographs Objects Histories, Routlege, New York.

Ehn Pelle, 1992, Scandinavian Design: On Participation and Skill, w: Paul S. Adler, Terry A. Winograd (red.), Usability: Turning Technologies into Tools, Oxford University Press, New York.

Frąckowiak Maciej, Rogowski Łukasz, 2009, W poszukiwaniu polskiej socjologii wizualnej, „Kultura i Społeczeństwo”, nr 1.

Frysztacki Krzysztof, 1996, Rozwój, wtaściwości i znaczenie socjologii stosowanej, w: Krzysztof Frysztacki (red.), Z zagadnień socjologii stosowanej, Universitas, Kraków.

Frysztacki Krzysztof, 2009, Socjologia problemów społecznych, Scholar, Warszawa.

Garfinkel Harold, 1984, Racjonalne cechy dziatalności naukowej i potocznej, w: Edmund Mokrzycki (red.), Kryzys i schizma. Antyscjentystyczne tendencje w socjologii wspótczesnej, PIW, Warszawa.

Gell Alfred, 1998, Art and Agency: An Anthropological Theory, Clarendon Press, Oxford.

Gliński Piotr, 1980, Badania aktywizujące w studiach stylu życia, w: Andrzej Siciński (red.), Problemy teoretyczne i metodologiczne badań stylu życia, Instytut Filozofii i Socjologii PAN, Warszawa.

Godlewski Grzegorz, 2008, Animacja i antropologia: następna generacja, w: Lokalnie: Animacja kultury/Community Arts, Instytut Kultury Polskiej Uniwersytetu Warszawskiego, Warszawa.

Giddens Anthony, 2001, Nowoczesność i tożsamość. „Ja” i społeczeństwo w epoce późnej nowoczesności, tłum. Alina Szulżycka, Wydawnictwo Naukowe PWN, Warszawa.

Giddens Anthony, 2003, Stanowienie społeczeństwa. Zarys teorii strukturacji, tłum. Stefan Amsterdamski, Zysk i S-ka, Poznań.

Habermas Jürgen, 2008, Strukturalne przeobrażenia sfery publicznej, tłum. Wanda Lipnik, Małgorzata Łukasiewicz, Wydawnictwo Naukowe PWN, Warszawa.

Harding Thomas, 1997, The Video Activist Handbook, Pluto Press, London.

Heath Christian, Knoblauch Hubert, Luff Paull, 2000, Technology and Social Interaction: The Emergence of “Workplace Studies”, „British Journal of Sociology”, t. 51, s. 299-320 .

Heidegger Martin, 1977, Czas światoobrazu, tłum. Krzysztof Wolicki, w: Krzysztof Michalski (red.), Martin Heidegger. Budować, mieszkać, myśleć. Eseje wybrane, Czytelnik, Warszawa.

Janowski Piotr, Kula Paweł, Noniewicz Marek, 2002, Świat. Fotografie dzieci z Jasionki i Krzywej, Wydawnictwo Czarne, Wołowiec.

Kaufmann Jean-Claude, 2004, Ego. Socjologia jednostki. Inna wizja człowieka i konstrukcji podmiotu, tłum. Krzysztof Wakar, Oficyna Naukowa, Warszawa. 
Kracauer Siegfried, 2010, Od Caligariego do Hitlera. Z psychologii filmu niemieckiego, tłum. Eugenia Skrzywanowa, Słowo/obraz terytoria, Gdańsk.

Krajewski Marek, 2007, Postepy i przedmioty, w: Michał Staniszewski (red.), Miasto postępu, Forum Naukowe, Poznań.

Krajewski Marek, 2008a, Ludzie i przedmioty - relacje i motywy przewodnie, w: Jacek Kowalewski, Wojciech Piasek, Marta Śliwa (red.), Rzeczy i ludzie. Humanistyka wobec materialności, Instytut Filozofii Uniwersytetu Warmińsko-Mazurskiego, Olsztyn.

Krajewski Marek, 2008b, Fotografie jako przedmioty, w: Jerzy Kaczmarek (red.), Do zobaczenia. Socjologia wizualna $w$ praktyce badawczej, Wydawnictwo Naukowe UAM, Poznań.

Kwon Miwon, 2004, One Place after Another: Site-Specific Art and Locational Identity, The MIT Press, Cambridge-London.

Latour Bruno, 1990, Visualisation and Cognition: Drawing Things Together, w: Michael Lynch, Steve Woolgar (red.), Representation in Scientific Practice, The MIT Press, Cambridge-London.

Latour Bruno, 2009, Polityka natury. Nauki wkraczaja do demokracji, tłum. Agata Czarnecka, Wydawnictwo Krytyki Politycznej, Warszawa.

Latour Bruno, 2010, Splatajac na nowo to, co spoteczne. Wprowadzenie do teorii aktora-sieci, tłum. Aleksandra Derra, Krzysztof Abriszewski, Universitas, Kraków.

Latour Bruno, 2011, Nigdy nie byliśmy nowocześni, tłum. Maciej Gdula, Oficyna Naukowa, Warszawa.

Lutz Catherine, Collins Jane L., 1993, Reading National Geographic, University of Chicago Press, Chicago.

MacDougall David, 1975, Beyond Observational Cinema, w: Paul Hockings (red.), Principles of Visual Anthropology, Mouton, Hague.

Mead Margaret, 2000 [1953], The Study of Culture at a Distance, w: Margaret Mead, Rhoda Métraux, The Study of Culture at a Distance, Berghahn, Oxford.

Mills C. Wright, 2008 Wyobraźnia socjologiczna, tłum. Marta Bucholc, Wydawnictwo Naukowe PWN, Warszawa.

Mitchell Claudia, 2008, Getting the Picture and Changing the Picture: Visual Methodologies and Educational Research in South Africa, „South African Journal of Education”, t. 28, s. 365-368.

Mitchell Claudia, 2011, Doing Visual Research, Sage, London.

Mucha Janusz, 1986, Socjologia jako krytyka spoteczna. Orientacja radykalna $i$ krytyczna we wspótczesnej socjologii zachodniej, PIW, Warszawa.

Pater-Ejgierd Natalia, 2010, Kultura wizualna a edukacja, Fundacja Tranzyt, Poznań.

Pinney Christopher, 2004, "Photos of the Gods": The Printed Image and Political Struggle in India, Reaktion Books, London.

Pink Sarah, 2004, Home Truths: Gender, Domestic Objects and Everyday Life, Oxford-New York.

Pink Sarah, 2006, The Future of Visual Anthropology: Engaging the Senses, Routledge, Abingdon-New York.

Pink Sarah (red.), 2007, Visual Interventions: Applied Visual Anthropology, Berghahn, New York-Oxford.

Pink Sarah, 2008, Mobilizing Visual Ethnography: Making Routes, Making Place and Making Images, „Forum: Qualitative Social Research”, t. 9, nr 3.

Rieger John H., 1996, Photographing Social Change, „Visual Sociology”, t. 11, s. 5-49. 
Rieger John H., 2003, A Retrospective Visual Study of Social Change: The Pulp-logging Industry in a Upper Peninsula Michigan County, „Visual Studies”, t. 18, s. 157-178.

Rogowski Łukasz, 2010, Kompetencja wizualna. Zarys problematyki i propozycja ujęcia, „Kultura Współczesna, nr 4.

Rouillé Andre, 2007, Fotografia. Między dokumentem a sztuka wspótczesna, tłum. Oskar Hedemann, Universitas, Kraków.

Rosenblum Naomi, 2005, Historia fotografii światowej, tłum. Inez Baturo, Baturo Grafis Projekt, Bielsko-Biała.

Sanders Elizabeth B., Stappers Pieter J., 2008, Co-creation and the New Landscapes of Design, “CoDesign", t. 4, nr 1, s. 5-18.

Schütz Alfred, 2008, O wielości światów: szkice z socjologii fenomenologicznej, tłum. Barbara Jabłońska, Nomos, Kraków.

Sperschneider Werner, 2007, Video Ethnography under Industrial Constraints: Observational Techniques and Video Analysis, w: Sarah Pink (red.), Visual Interventions: Applied Visual Anthropology, Berghahn, New York-Oxford.

Tagg John, 2009, The Disciplinary Frame: Photographic Truths and the Capture of Meaning, University of Minnesota Press, Minneapolis.

Turner Terence, 1992, Defiant Images: The Kayapo Appropriation of Video, „Anthropology Today", t. 8, s. 5-16.

Waltz Mitzi, 2005, Alternative and Activist Media, Edinburgh University Press, Edinburgh.

Welzer Herald, 2010, Wojny klimatyczne. Za co będziemy zabijać w XXI wieku, tłum. Michał Sutowski, Wydawnictwo Krytyki Politycznej, Warszawa.

Wright Terence, 1999, The Photography Handbook, Routledge, New York.

Wright Terence, 2008, Visual Impact: Culture and the Meaning of Images, Berg, Oxford-New York.

Van Dienderen An, 2007, Performing Urban Collectivity: Ethnography of the Production Process of a Community-based Film Project in Brussels, w: Sarah Pink (red.), Visual Interventions: Applied Visual Anthropology, Berghahn, New York-Oxford.

THE PICTURE IN ACTION:

INTERVENTIONAL STRATEGIES OF CONTEMPORARY VISUAL RESEARCH

\section{Sum mary}

The topic of this article is the reconstruction of the scope of the contemporary use of visual investigative methods. It begins with a discussion of the social changes and changes of social theory which have led to a substantial redefinition of the form of video and visual techniques for intervention activities applied by the social sciences. Such activities are based on a greater degree of participation of those who will make use of them than was usual in the past, the technology of the creation and distribution of images is much more widespread, and also there has been an important change in the definition of technical images for the use of the social sciences - these all allow their contemporary utilisation, and are described by the author in the form of five models of strategy: advocacy, cultural representation, the animation of local communities, education in visual competence and control of values and safety. In the second part of the article they are presented using selected and representative examples. 


\section{Key words/słowa kluczowe}

visual research / badania wizualne; applied social sciences / stosowane nauki społeczne; advocacy / rzecznictwo; cultural representation / pośrednictwo kulturowe; emancipation of local communities / emancypacja wspólnot lokalnych; visual competence / kompetencja wizualna 